\title{
P4HB modulates epithelial-mesenchymal transition and the $\beta$-catenin/Snail pathway influencing chemoresistance in liver cancer cells
}

\author{
XING MA $^{1 *}$, JIENING WANG $^{2 *}$, JUHUA ZHUANG $^{1}$, XIAOKUN MA $^{1}$, NI ZHENG ${ }^{1}$, YANAN SONG $^{2}$ and WEI XIA ${ }^{1}$ \\ ${ }^{1}$ Department of Nuclear Medicine; ${ }^{2}$ Central Laboratory, The Seventh People's Hospital of \\ Shanghai University of Traditional Chinese Medicine, Shanghai 200137, P.R. China
}

Received July 4, 2019; Accepted January 15, 2020

DOI: $10.3892 / \mathrm{ol} .2020 .11569$

\begin{abstract}
The aim of the present study was to investigate the role of prolyl 4-hydroxylase beta polypeptide (P4HB) in the chemoresistance of liver cancer. Drug-resistant liver cancer cell lines, such as HepG2/adriamycin (ADR) cells, were treated and screened using adriamycin. Gene interference was used to silence the expression of $P 4 H B$ in liver cancer cells. Cell viability, invasiveness and migration were assessed using CCK8, Transwell and wound healing assays, respectively. In addition, changes to key genes and proteins in the epithelial-mesenchymal transition (EMT) and $\beta$-catenin/Snail pathway were analyzed using reverse transcription-quantitative PCR and western blotting. Drug-resistant HepG2/ADR cells were successfully cultivated; the $\mathrm{IC}_{50}$ to ADR for HepG2/ADR and HepG2 cell lines was 4.85 and $0.61 \mu \mathrm{M}$, respectively. HepG2/ADR cells exhibited higher invasion and migration abilities compared with HepG2 cells $(\mathrm{P}<0.05)$. E-cadherin mRNA and protein expression levels in HepG2/ADR cells were decreased significantly, whereas $\mathrm{P} 4 \mathrm{HB}, \mathrm{N}$-cadherin and vimentin mRNA and protein levels were significantly increased compared with HepG2 cells (all $\mathrm{P}<0.05$ ). Knockdown of P4HB significantly decreased cell viability and the invasion and migration ability of HepG2/ADR cells. In addition, P4HB knockdown enhanced
\end{abstract}

Correspondence to: Professor Wei Xia, Department of Nuclear Medicine, The Seventh People's Hospital of Shanghai University of Traditional Chinese Medicine, 358 Datong Road, Pudong, Shanghai 200137, P.R. China

E-mail: awingxia@163.com

Professor Yanan Song, Central Laboratory, The Seventh People's Hospital of Shanghai University of Traditional Chinese Medicine, 358 Datong Road, Pudong, Shanghai 200137, P.R. China E-mail: synabc.123@163.com

${ }^{*}$ Contributed equally

Key words: $\mathrm{P} 4 \mathrm{HB}$, liver cancer, chemoresistance, epithelialmesenchymal transition, $\beta$-catenin/Snail pathway
E-cadherin mRNA and protein expression levels, whereas $\mathrm{N}$-cadherin, vimentin, total $\beta$-catenin, nuclear $\beta$-catenin and Snail mRNA and protein levels were significantly decreased (all $\mathrm{P}<0.05)$. Overall, the present study demonstrated that EMT and $\beta$-catenin/Snail pathway influence P4HB modulation in liver cancer chemoresistance.

\section{Introduction}

Liver cancer is the sixth most common cancer and is the second leading cause of cancer-associated mortality worldwide in $2018(1,2)$. Chemotherapy is one of the most common treatment methods for liver cancer $(3,4)$; however, it is not very efficacious in certain patients (5). Currently, transarterial chemoembolization (TACE) is the preferred therapy for patients with advanced hepatocellular carcinoma (HCC) (6). Adriamycin (ADR), also known as doxorubicin, is the first-line chemotherapeutic drug used in TACE (7). However, the prognosis of patients with HCC remains poor due to inherent or acquired chemoresistance to Adriamycin $(8,9)$. Understanding the molecular mechanisms underlying ADR resistance in liver cancer may result in improved liver cancer prognosis and the development of suitable therapeutic targets to overcome chemoresistance.

Prolyl 4-hydroxylase beta polypeptide $(P 4 H B)$ is the core member of the protein disulfide isomerase gene family, and can serve as an endoplasmic reticulum chaperone to inhibit the aggregation of misfolded proteins (10). Previous reports have demonstrated that overexpression of $\mathrm{P} 4 \mathrm{HB}$ promotes liver cancer progression via the upregulation of epithelial-mesenchymal transition (EMT) (11), which is closely associated with drug-resistance in malignant gliomas (12), glioblastoma multiforme (13) and non-small cell lung cancer (14). However, whether $P 4 H B$ regulates drug-resistance in liver cancer is unknown.

EMT was initially considered to be an important physiological process in tissue differentiation and organogenesis during embryonic development (15). Previous studies have revealed that EMT is closely associated with drug-resistance and tumor metastasis $(16,17)$. EMT occurs in both gemcitabine-resistant pancreatic adenocarcinoma cell lines (such as MiaPaCa-2, Panc-1 and Aspc-1) (18) and adriamycin-induced drug-resistant 
breast cancer cells (such as MCF7) (19). Snail and $\beta$-catenin are two of the several known regulators of EMT-associated. Snail is a zinc finger transcription factor and an important regulator in tumor progression, which can promote tumor invasion and metastasis (20). Overexpression of Snail can promote epithelial mesenchymal transformation and the invasion and migration of breast cancer cells (21). Snail-induced EMT is partly due to the direct repression of E-cadherin transcription both during development and tumour progression (22). $\beta$-catenin serves a key role in regulating cell proliferation and differentiation $(23,24)$. Epithelial integrity requires the stability of E-cadherin/ $\beta$-catenin complexes (25). Previous studies have reported that Snail, $\beta$-catenin and EMT contribute to tumor chemotherapeutic resistance to sorafenib (26) and cisplatin (27-29).

In the present study, the expression of P4HB was measured in drug-resistant liver cancer cells and its effects on invasion, migration and chemoresistance were investigated. The aim was to investigate the therapeutic value of targeting $P 4 H B$ for liver cancer therapy.

\section{Materials and methods}

Cell culture. The liver cancer cell line HepG2 was purchased from The Cell Bank of Type Culture Collection of the Chinese Academy of Sciences. Dulbecco's modified Eagle's medium (DMEM; Invitrogen; Thermo Fisher Scientific, Inc.), supplemented with $10 \%$ fetal bovine serum (FBS; Invitrogen; Thermo Fisher Scientific, Inc.), $100 \mathrm{U} / \mathrm{ml}$ penicillin (Invitrogen; Thermo Fisher Scientific, Inc.) and $100 \mu \mathrm{g} / \mathrm{ml}$ streptomycin (Invitrogen; Thermo Fisher Scientific, Inc.), was used as the cell culture medium. Cells were cultured in a humidified chamber containing $5 \% \mathrm{CO}_{2}$ at $37^{\circ} \mathrm{C}$. To establish the HepG2/ADR cell lines, ADR (Selleckchem Chemicals) was added to HepG2 cells in a stepwise increasing titration from $0.001-0.5 \mathrm{mg} / \mathrm{l}$ for 6 months. Resistant cell colonies were subsequently obtained. Adriamycin resistance was maintained by culturing the cells at low concentrations of ADR $(0.10 \mathrm{mg} / \mathrm{l})$. These resistant sub-lines were named HepG2/ADR. At least three independent experiments were performed.

Cell proliferation studies. Cell Counting Kit-8 (CCK-8; Beyotime Biotechnology, Inc.) assays were used to assess drug sensitivity. HepG2 and HepG2/ADR cells were seeded into 96-well plates at a density of 3,000 cells/well. HepG2/ADR cells were cultured in fresh medium containing increased concentrations of adriamycin (from 0-8 $\mu \mathrm{M}$ ) substituted medium and incubated at $37^{\circ} \mathrm{C}$ with $5 \% \mathrm{CO}_{2}$ for $48 \mathrm{~h}$. CCK- 8 assay was performed according to the manufacturer's protocols. Briefly, each well was treated with $10 \mathrm{ul} \mathrm{CCK-8}$ reagent. After incubating at $37^{\circ} \mathrm{C}$ for additional $2 \mathrm{~h}$, the optical density at a wavelength of $450 \mathrm{~nm}$ was determined using a Spectramax M5 microplate reader (Molecular Devices, LLC). Each assay was performed with 5 replications.

Transwell migration and invasion assays. The Transwell chambers used for the migration assay contained polycarbonate filters with a $8-\mu \mathrm{m}$ pore size (BD Biosciences). DMEM containing $10 \%$ FBS was placed in the lower chambers. HepG2 and HepG2/ADR cells ( $1 \times 10^{5}$ in $500 \mu 1$ serum-free DMEM) were seeded onto the upper chamber and incubated at $37^{\circ} \mathrm{C}$ for $24 \mathrm{~h}$. Cells that had migrated to the lower chambers were fixed with $70 \%$ methanol and then stained with $0.1 \%$ crystal violet at room temperature, and imaged using an Olympus ix 71 light microscope at x100 magnification (Olympus Corporation, Inc.).

In order to measure cell invasion, $1 \times 10^{5} \mathrm{HepG} 2$ and HepG2/ADR cells were serum-starved overnight and seeded onto the upper chamber precoated with Matrigel (for $30 \mathrm{~min}$ at $37^{\circ} \mathrm{C}$ ). The cells that penetrated the Matrigel-coated filter were fixed, stained, and counted as aforementioned, and subsequently five cell fields were randomly selected from each membrane to count using an Olympus ix 71 light microscope at x100 magnification (Olympus Corporation, Inc.). Each assay was performed in triplicate. At least three independent experiments were performed.

Wound healing assay. HepG2 and HepG2/ADR cells were seeded onto 6 -well plates at a density of $5 \times 10^{5}$ cells/well and cultured in a humidified chamber containing $5 \% \mathrm{CO}_{2}$ at $37^{\circ} \mathrm{C}$ for one day. After the cells reached $100 \%$ confluence, a line was scraped at the center of each well using a 200-ul pipette tip. Cellular debris was then carefully removed by washing with PBS three times. Subsequently, cells were cultured in serum-free medium at $5 \% \mathrm{CO}_{2}$ and $37^{\circ} \mathrm{C}$ for $24 \mathrm{~h}$. The images of the confluent cells were captured using an Olympus ix 71 light microscope at x100 magnification (Olympus Corporation, Inc.) to determine the wound width at time 0 and $24 \mathrm{~h}$, respectively. Wound healing was visualized by comparing the images taken at 0 and $24 \mathrm{~h}$, and analyzing the migration distance using the leading edge of the wound at each time point for all the treatment groups. The relative wound width was calculated as wound width at $24 \mathrm{~h}$ divided by wound width at the $0 \mathrm{~h}$ time point. At least three independent experiments were performed.

Western blotting. After treatment, total cellular protein from HepG2 and HepG2/ADR cells was extracted using RIPA buffer containing $1 \mathrm{mM}$ phenylmethanesulfonyl fluoride (Aidlab Biotechnologies Co., Ltd.). Cell lysates were collected, and protein concentrations were determined using the bicinchoninic acidprotein assay kit (Beyotime Biotechnology, Inc.). Cell lysates ( $40 \mu \mathrm{g}$ total protein and $40 \mu \mathrm{g}$ nuclear protein) were subsequently separated by SDS-PAGE (10\% gel) and transferred onto PVDF membranes (Bio-Rad Laboratories, Inc.). Next, $5 \%$ fat-free milk was used to block the membrane at $4^{\circ} \mathrm{C}$ for $1 \mathrm{~h}$. Membranes were then incubated overnight with different primary antibodies including anti-P4HB (1:1,000; cat. no. ab137110; Abcam), anti-E-cadherin (1:1,000; cat. no. 3195; Cell Signaling Technology, Inc.), anti-N-cadherin (1:1,000; cat. no. 4061; Cell Signaling Technology, Inc.), anti-vimentin (1:1,000; cat. no. 5741; Cell Signaling Technology, Inc.), anti-Snail (1:1,000; cat. no. 3879; Cell Signaling Technology, Inc.), anti- $\beta$-catenin (1:1,000; cat. no. 8480; Cell Signaling Technology, Inc.), anti- $\beta$-actin (1:1,000; cat. no. 4970; Cell Signaling Technology, Inc.) or anti-histone H3 (1:1,000; cat. no. ab1791; Abcam) at $4^{\circ} \mathrm{C}$. $\beta$-Actin and histone proteins were used as the internal controls for total protein and nuclear protein, respectively. After washing, the membranes were incubated with the corresponding HRP-linked secondary antibody (1:5,000; cat. no. 7074; Cell Signaling Technology, Inc.) at room temperature for $1 \mathrm{~h}$. Protein bands were visualized with an enhanced chemiluminescent 

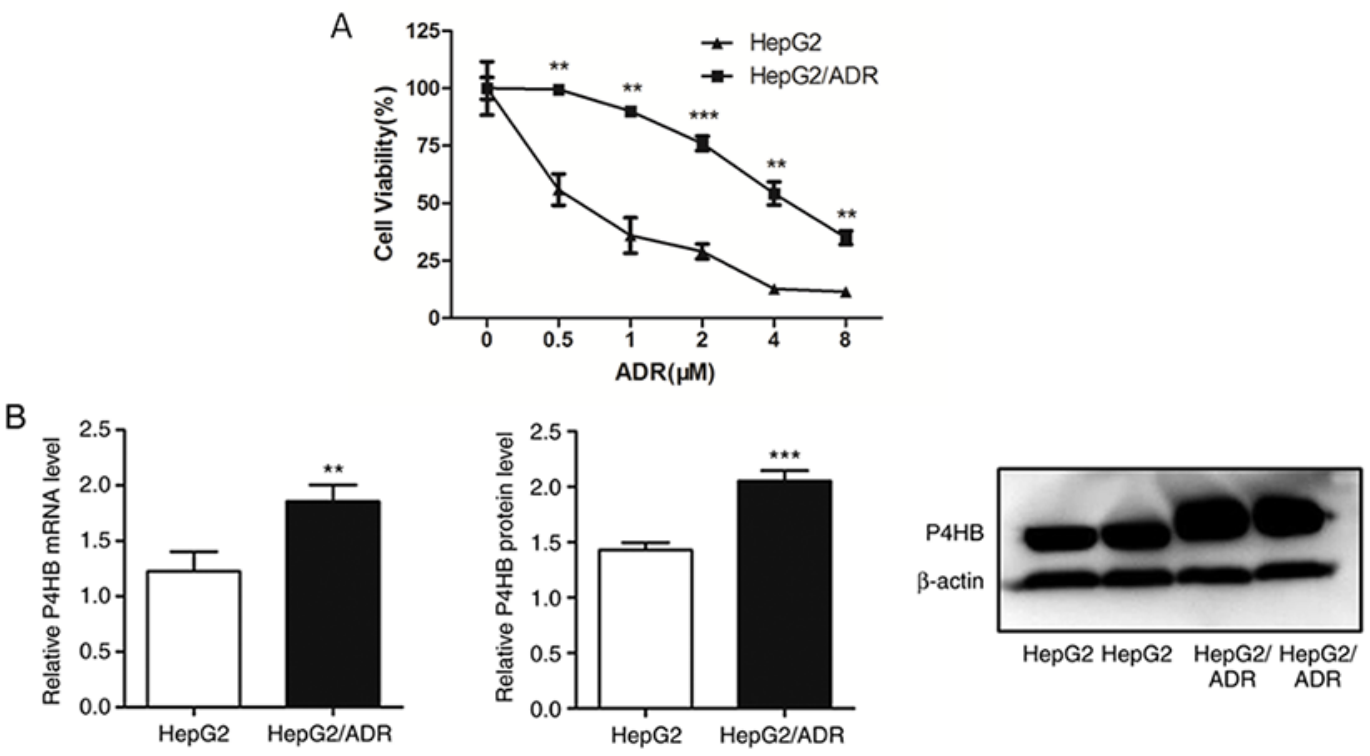

Figure 1. P4HB expression levels and the different chemosensitivities of liver cancer cell lines. (A) HepG2/ADR cells have higher resistance to ADR compared with the parental HepG2 cell line ( $\mathrm{IC}_{50}$ of HepG2/ADR cells is 8 times higher, as determined using Cell Counting Kit-8 assays). (B) P4HB mRNA and protein expression levels as determined by reverse transcription-quantitative PCR and western blotting, respectively. Experiments were performed in triplicate. ${ }^{* *} \mathrm{P}<0.01,{ }^{* * *} \mathrm{P}<0.001$ vs. HepG2. $\mathrm{P} 4 \mathrm{HB}$, prolyl 4-hydroxylase beta polypeptide; ADR, adriamycin.

reagent (GE Healthcare). Band intensity was measured using the gel imaging system (ProteinTech Group, Inc.) and analyzed using the FluorChem FC3 software (Proteinsimple, Inc.). At least three independent experiments were performed.

Reverse transcription-quantitative (RT-qPCR). Total RNA was isolated from HepG2 and HepG2/ADR liver cancer cells using TRIzol ${ }^{\circledR}$ reagent (Invitrogen; Thermo Fisher Scientific, Inc.), according to the manufacturer's instructions. RNA concentration was determined using the NanoDrop 2000 spectrophotometer (Thermo Fisher Scientific, Inc.). According to the manufacturer's instructions, a total of $1 \mu \mathrm{g}$ RNA was reverse-transcribed (at $42^{\circ} \mathrm{C}$ for $1 \mathrm{~h}$; and at $70^{\circ} \mathrm{C}$ for $10 \mathrm{~min}$ ) using the First-Strand cDNA Synthesis kit (Invitrogen; Thermo Fisher Scientific, Inc.). qPCR was performed using a SYBR green qPCR SuperMix-UDG kit (Life Technologies; Thermo Fisher Scientific, Inc.) on an ABI 7500 system (Applied Biosystems; Thermo Fisher Scientific, Inc.) to determine the expression levels of the target mRNAs in accordance with the manufacturer's instructions $\left(95^{\circ} \mathrm{C}\right.$ for $10 \mathrm{sec} ; 60^{\circ} \mathrm{C}$ for $15 \mathrm{sec}$; $72^{\circ} \mathrm{C}$ for $15 \mathrm{sec} ; 45$ cycles).

Relative mRNA expression levels were calculated using GAPDH as the internal control. Each sample was run in triplicate. The primer pairs used were as follows: $\mathrm{P} 4 \mathrm{HB}$ forward, 5'-GGAATGGAGACACGGCTTC-3' and reverse, 5'-TTCAGCCAGTTCACGATGTC-3'; and $\beta$-actin forward, 5'-AGCGCGGCTACAGCTTCA-3', and reverse, 5'-GGCCAT CTCTTGCTCGAAGT-3'. The gene expression levels for all samples were normalized to GAPDH expression using the $2^{-\Delta \Delta \mathrm{Cq}}$ method (30). At least three independent experiments were performed.

Cell transfection. Small interfering RNA (siRNA) specific for human P4HB (5'-AAGATGAACTGTAATACGCAA-3') and a scrambled siRNA (5'-UUCUCCGAACGUGUCACG UTT-3'), which was used as the negative control (NC), were designed and synthesized by Shanghai GenePharma Co., Ltd. HepG2/ADR cells were seeded at a density of $3 \times 10^{5}$ cells $/ \mathrm{ml}$ onto 6-well plates and transfected with 2 ug control siRNA and P4HB siRNA using Lipofectamine ${ }^{\circledR} 2000$ (Invitrogen; Thermo Fisher Scientific, Inc.) according to the manufacturer's protocol for $48 \mathrm{~h}$. At least three independent experiments were performed.

Statistical analysis. Data are presented as mean \pm SD. Data was analyzed using the SPSS 21.0 software (IBM, Corp.). The Mann-Whitney U test was performed due to abnormal distribution or heterogeneity of variance. Additionally, the Student's t-test or one-way analysis of variance with Dunnett's post-hoc test was used for normally distributed data. $\mathrm{P}<0.05$ was considered to indicate a statistically significant difference.

\section{Results}

P4HB expression levels are upregulated in chemoresistant liver cancer sub-line HepG2/ADR. In order to investigate the possible mechanisms underlying chemoresistance in liver cancer, a liver cancer sub-line that is resistant to ADR was established. The liver cancer cell line HepG2/ADR was more resistant to ADR compared with its parental cell line (Fig. 1A). The half maximal inhibitory concentration $\left(\mathrm{IC}_{50}\right)$ of HepG2/ADR and HepG2 cell lines resistant to ADR were 4.85 and $0.61 \mu \mathrm{M}$, respectively. The data also revealed that $\mathrm{P} 4 \mathrm{HB}$ mRNA and protein levels were higher in HepG2/ADR cells compared with HepG2 cells $(\mathrm{P}<0.01$; Fig. 1B). This indicates that $\mathrm{P} 4 \mathrm{HB}$ may serve an important role in liver cancer chemoresistance.

Chemoresistant liver cancer subline exhibits an EMT phenotype with high migration and invasion abilities. To 

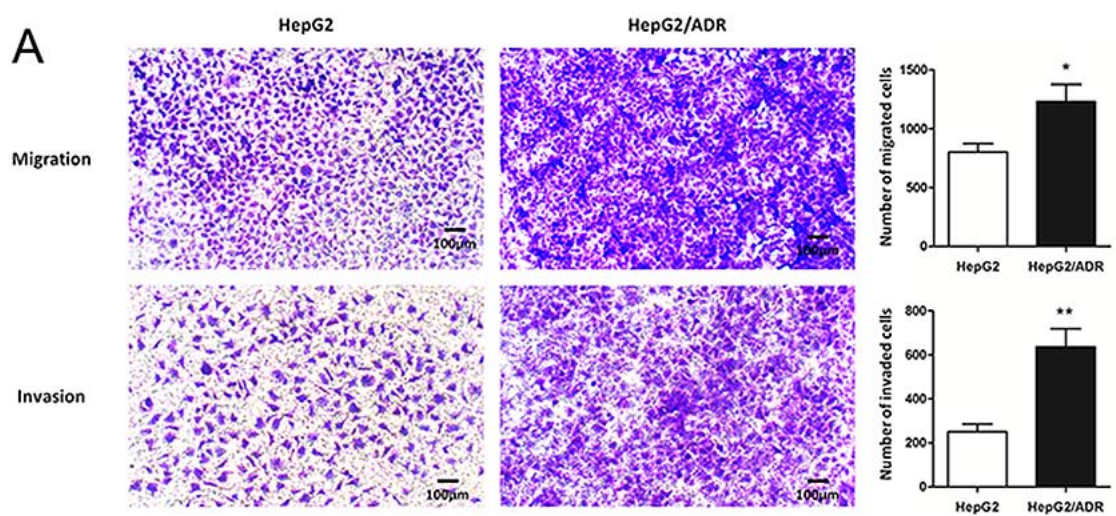

B
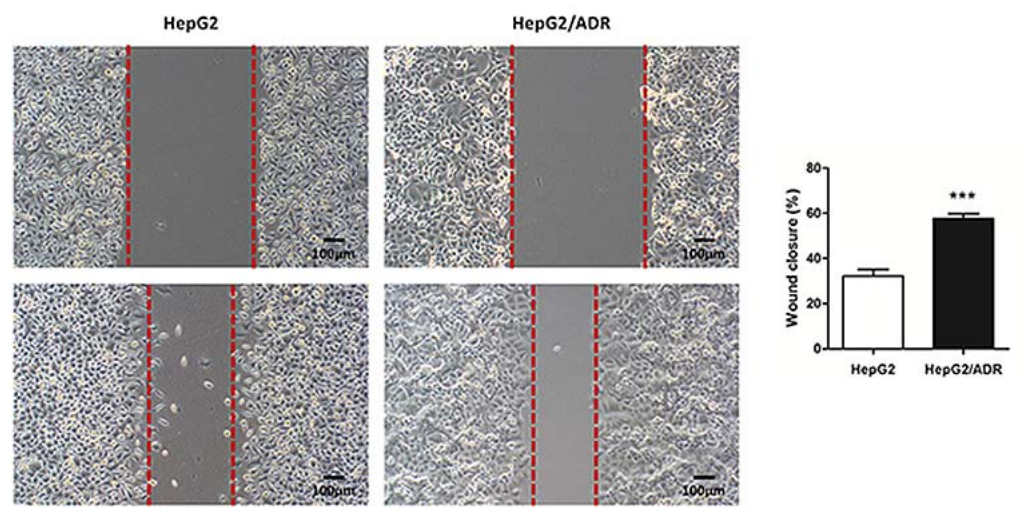

Figure 2. HepG2/ADR cells have increased migration and invasion abilities. (A) The number of migrating and invading HepG2/ADR cells, as determined by Transwell assays, were significantly higher compared with the parental HepG2 cell line after $24 \mathrm{~h}$. (B) HepG2/ADR cells had significantly increased numbers of migratory cells across the wound area compared with the parental HepG2 cell line after $24 \mathrm{~h}$. Experiments were performed in triplicate. Magnification, $\mathrm{x} 100 .{ }^{*} \mathrm{P}<0.05,{ }^{* *} \mathrm{P}<0.01,{ }^{* * *} \mathrm{P}<0.001$ vs. HepG2. P4HB, prolyl 4-hydroxylase beta polypeptide; ADR, adriamycin.
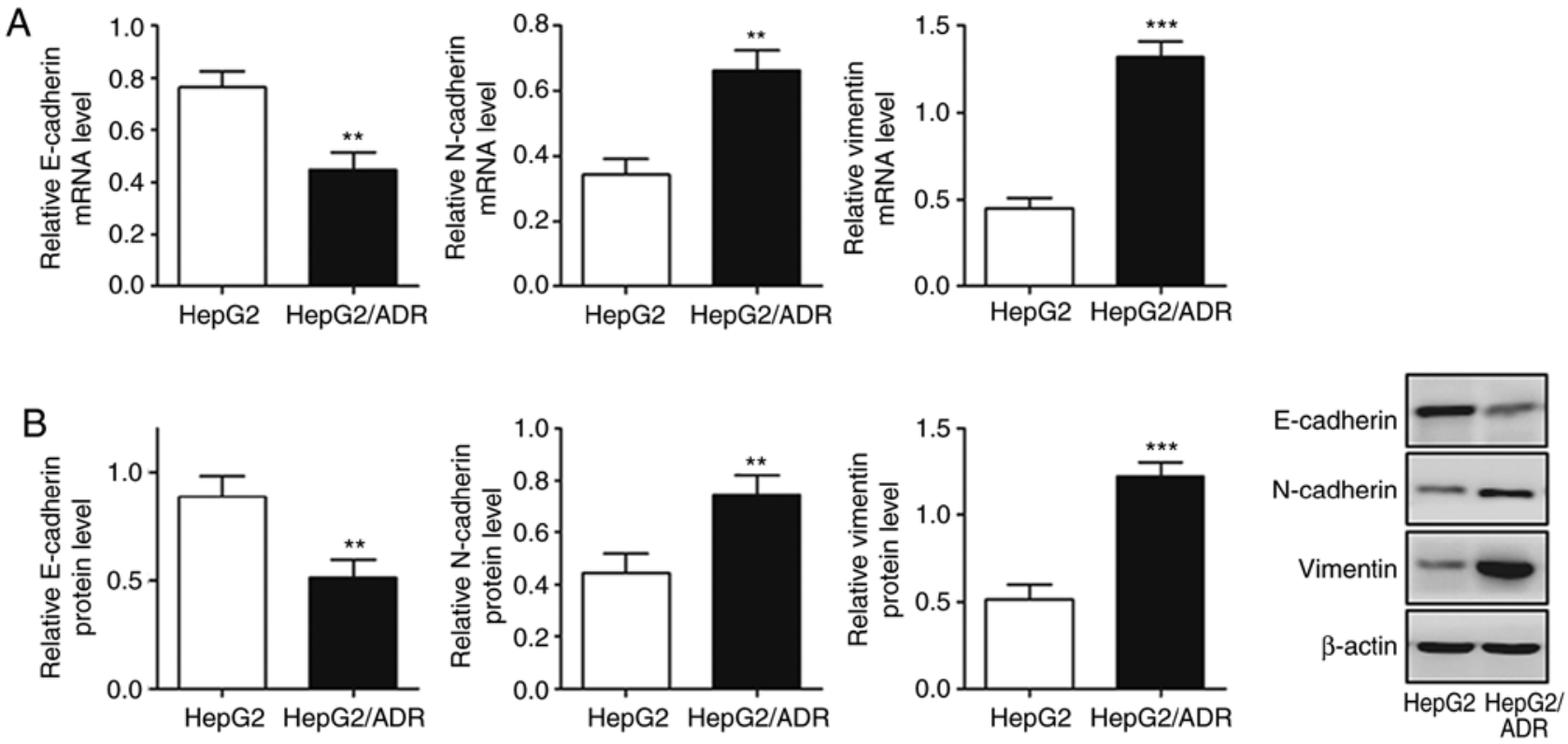

Figure 3. Chemoresistant liver cancer exhibits characteristics of epithelial-mesenchymal transition. (A) E-cadherin mRNA expression levels were significantly reduced in HepG2/ADR cells; however, vimentin and N-cadherin mRNA levels were significantly increased, compared with the parental HepG2 cell line, as demonstrated by reverse transcription-quantitative PCR. (B) Western blotting demonstrated that E-cadherin protein expression was significantly reduced in HepG2/ADR cells; however, vimentin and $\mathrm{N}$-cadherin protein levels were significantly increased compared with the parental HepG2 cell line. Experiments were performed in triplicate. ${ }^{*} \mathrm{P}<0.05,{ }^{* *} \mathrm{P}<0.01,{ }^{* * *} \mathrm{P}<0.001$ vs. HepG2. $\mathrm{P} 4 \mathrm{HB}$, prolyl 4-hydroxylase beta polypeptide; ADR, adriamycin.

determine the migration and invasion ability of HepG2/ADR cells, Transwell and wound healing assays were performed.
HepG2/ADR cells had significantly increased numbers of cells with migratory and invasive ability after $24 \mathrm{~h}$, compared 

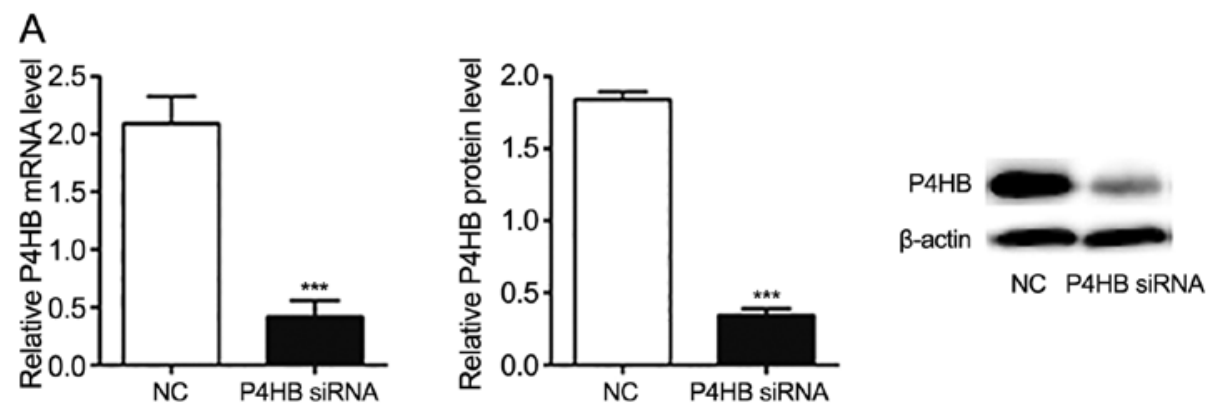

B

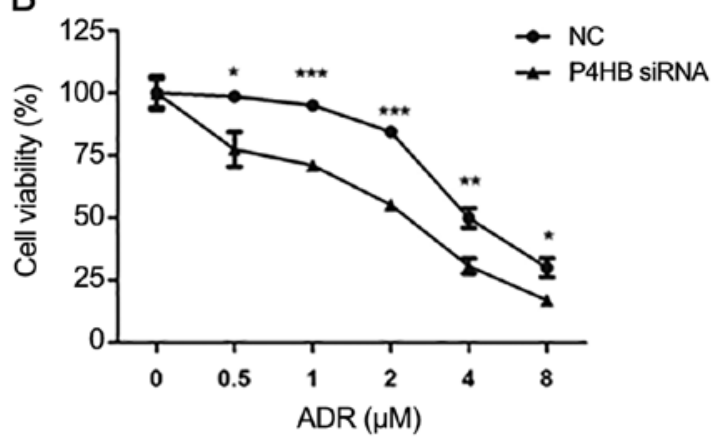

Figure 4. Knockdown of P4HB reduces drug-resistance in HepG2/ADR cells. (A) HepG2/ADR cells were transfected with P4HB and NC siRNA. P4HB protein and mRNA expression levels were significantly downregulated after P4HB siRNA transfection. (B) Cell viability in P4HB siRNA transfected cells were lower compared with the NC group ( $\mathrm{IC}_{50}$ in the NC group was 2.3 times higher compared with P4HB siRNA-transfected cells (as determined by Cell Counting Kit- 8 assays). Experiments were performed in triplicate. ${ }^{*} \mathrm{P}<0.05,{ }^{* *} \mathrm{P}<0.01,{ }^{* * *} \mathrm{P}<0.001$ vs. NC. P4HB, prolyl 4 -hydroxylase beta polypeptide; ADR, adriamycin; siRNA, small interfering RNA; NC, negative control; $\mathrm{IC}_{50}$, half maximal inhibitory concentration.

with HepG2 cells $(\mathrm{P}<0.05$; Fig. $2 \mathrm{~A}$ and $\mathrm{B})$, indicating that HepG2/ADR cells acquired enhanced migration and invasion ability. To determine whether HepG2/ADR cells acquired specific molecular changes consistent with EMT, the mRNA and protein expression levels of epithelial adhesion molecule E-cadherin and mesenchymal markers, including vimentin and $\mathrm{N}$-cadherin, were measured. It was observed that the expression of E-cadherin was significantly downregulated in HepG2/ADR cells at both mRNA and protein levels $(\mathrm{P}<0.01)$, whereas the expression levels of vimentin and $\mathrm{N}$-cadherin were upregulated $(\mathrm{P}<0.01$; Fig. 3). These results indicate that EMT was activated in adriamycin-resistant liver cancer cells.

Knockdown of $\mathrm{P} 4 \mathrm{HB}$ decreases drug-resistance in Hep G2/ADR cells. Following transfection of HepG2/ADR cells with $\mathrm{P} 4 \mathrm{HB}$ siRNA, the expression levels of $\mathrm{P} 4 \mathrm{HB}$ at the $\mathrm{mRNA}$ and protein levels were significantly downregulated ( $P<0.001$; Fig. 4A). Subsequently, the effect of $\mathrm{P} 4 \mathrm{HB}$ inhibition on ADR resistance was investigated in HepG2/ADR cells. CCK-8 assays demonstrated that ADR was more effective in cells transfected with $P 4 H B$ siRNA compared with cells transfected with NC siRNA. The $\mathrm{IC}_{50}$ of the NC group and the $P 4 H B$ siRNA group of ADR resistant cells were 4.64 and $2.05 \mu \mathrm{M}$, respectively (Fig. 4B). These findings suggest that knockdown of $\mathrm{P} 4 \mathrm{HB}$ partially reverses drug-resistance in liver cancer cell lines.

Knockdown of $P 4 H B$ inhibits the migration and invasion of HepG2/ADR cells. To further understand the role of $\mathrm{P} 4 \mathrm{HB}$, the migration and invasive abilities of HepG2/ADR cells transfected with $P 4 H B$ siRNA were investigated. Transwell assays demonstrated that knockdown of P4HB significantly decreased the migratory and invasive ability of HepG2/ADR cells $(\mathrm{P}<0.001$; Fig. 5A). Consistent with these results, $P 4 H B$ siRNA inhibited cell motility as assessed by wound healing assays in HepG2/ADR cells ( $\mathrm{P}<0.001$; Fig. 5B).

Knockdown of P4HB influences EMT in HepG2/ADR cells. It was observed that the expression levels of vimentin and $\mathrm{N}$-cadherin decreased $(\mathrm{P}<0.05)$, whereas E-cadherin levels increased significantly in HepG2/ADR cells transfected with $P 4 H B$ siRNA $(\mathrm{P}<0.05$; Fig. $6 \mathrm{~A}, \mathrm{~B})$. This suggests that the downregulation of $\mathrm{P} 4 \mathrm{HB}$ leads to the inhibition of EMT.

Knockdown of $\mathrm{P} 4 \mathrm{HB}$ inhibits the Snail and $\beta$-catenin pathways in HepG2/ADR cells. To investigate the pathway interaction between $\mathrm{P} 4 \mathrm{HB}$, Snail and $\beta$-catenin, the expression level changes in Snail and $\beta$-catenin were measured by western blotting after silencing $\mathrm{P} 4 \mathrm{HB}$ expression in vitro. It was observed that the knockdown of $\mathrm{P} 4 \mathrm{HB}$ significantly decreased the expression of total and nuclear $\beta$-catenin $(\mathrm{P}<0.01)$ and downregulated the expression of Snail $(\mathrm{P}<0.05)$ (Fig. 7). This indicates that $\mathrm{P} 4 \mathrm{HB}$ may influence the EMT process via the Snail and $\beta$-catenin pathways (Figs. 7 and 8 ).

\section{Discussion}

Liver cancer is one of the most common malignant tumors worldwide in $2018(1,2)$. Resistance to cytotoxic agents is the major cause of treatment failure in liver cancer. Several studies have demonstrated that $P 4 H B$ is associated with chemoresistance (14-16). The present study aimed to investigate whether $P 4 H B$ influences liver cancer chemotherapy resistance. It was 

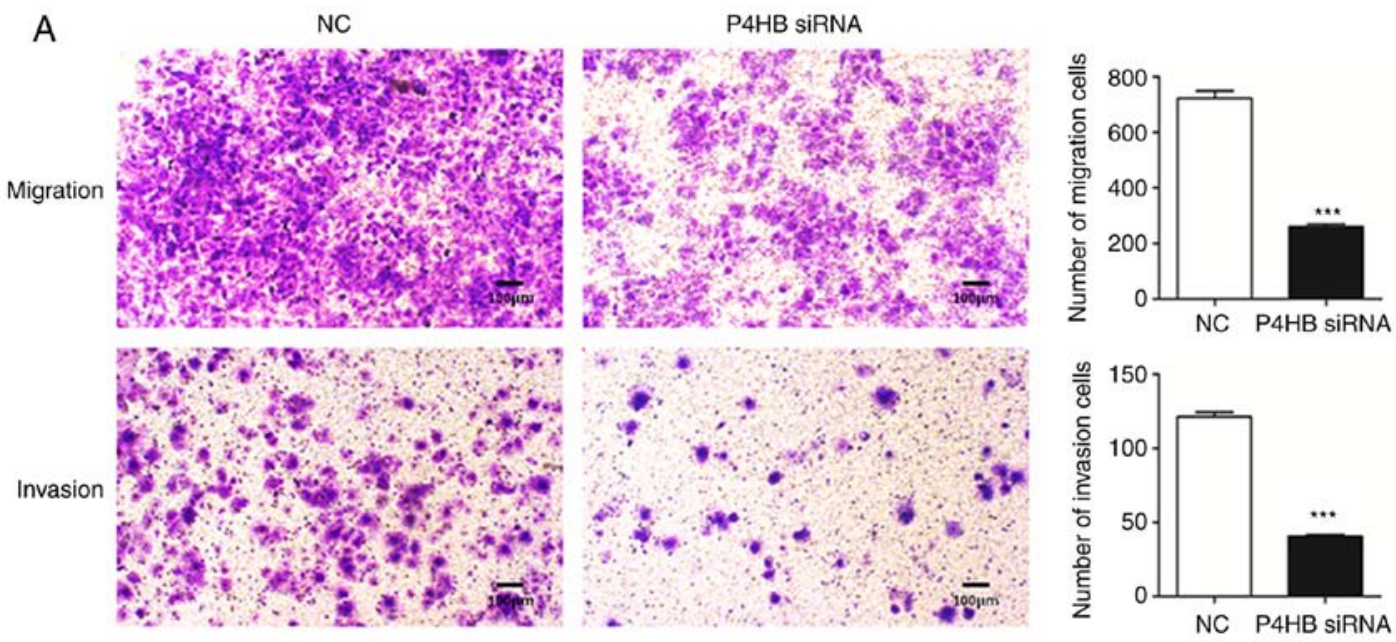

B

NC

P4HB siRNA
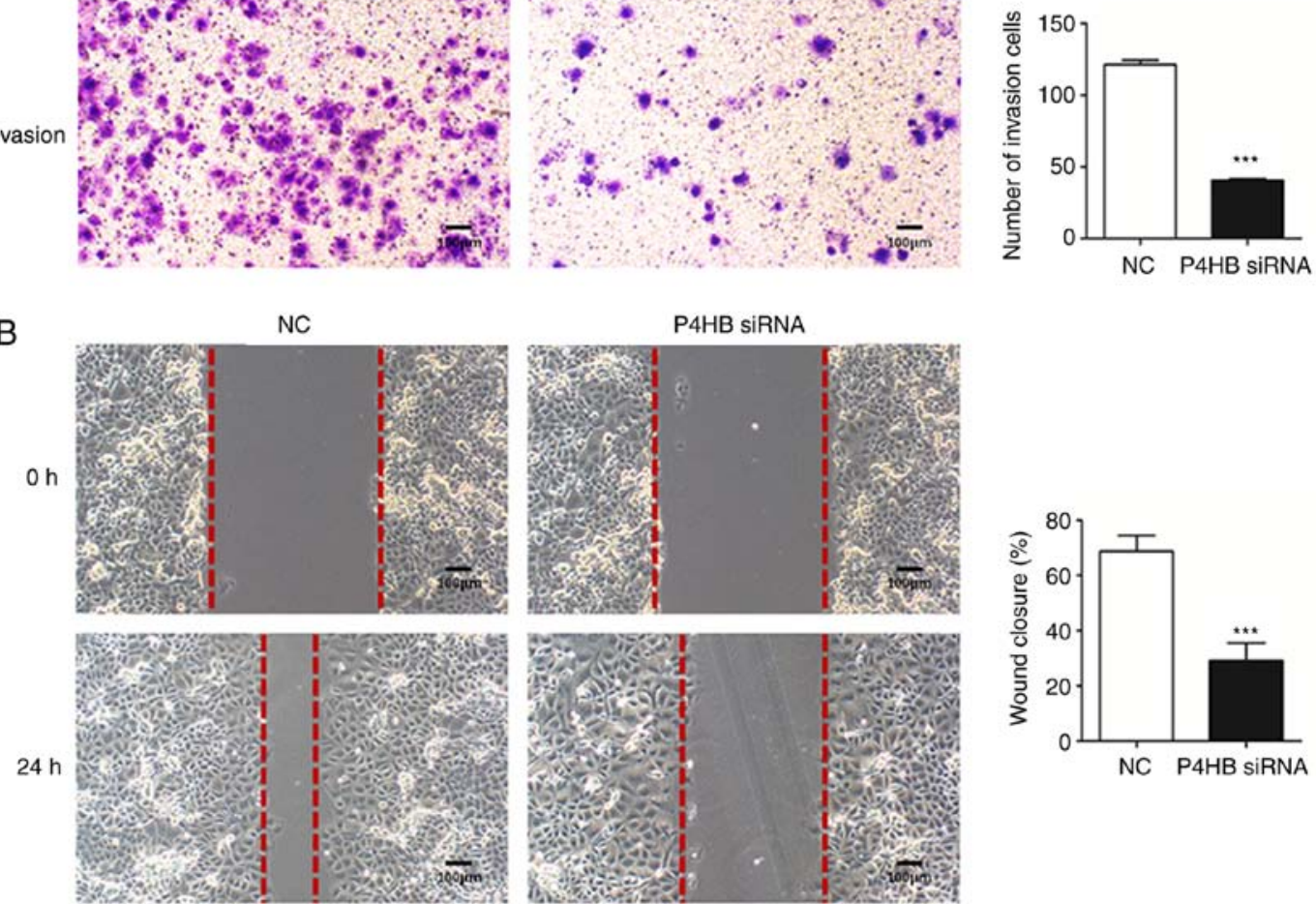

Figure 5. Knockdown of P4HB inhibits the migration and invasion of HepG2/adriamycin cells. (A) The numbers of migrating and invading cells were significantly reduced in the P4HB siRNA group compared with the NC group after $24 \mathrm{~h}$. (B) The P4HB siRNA group had significantly reduced number of cells migrating across the wound area compared with the NC group after $24 \mathrm{~h}$. Experiments were performed in triplicate. Magnification, $\mathrm{x} 100 .{ }^{* * *} \mathrm{P}<0.001 \mathrm{vs}$. NC. P4HB, prolyl 4-hydroxylase beta polypeptide; siRNA, small interfering RNA; NC, negative control.
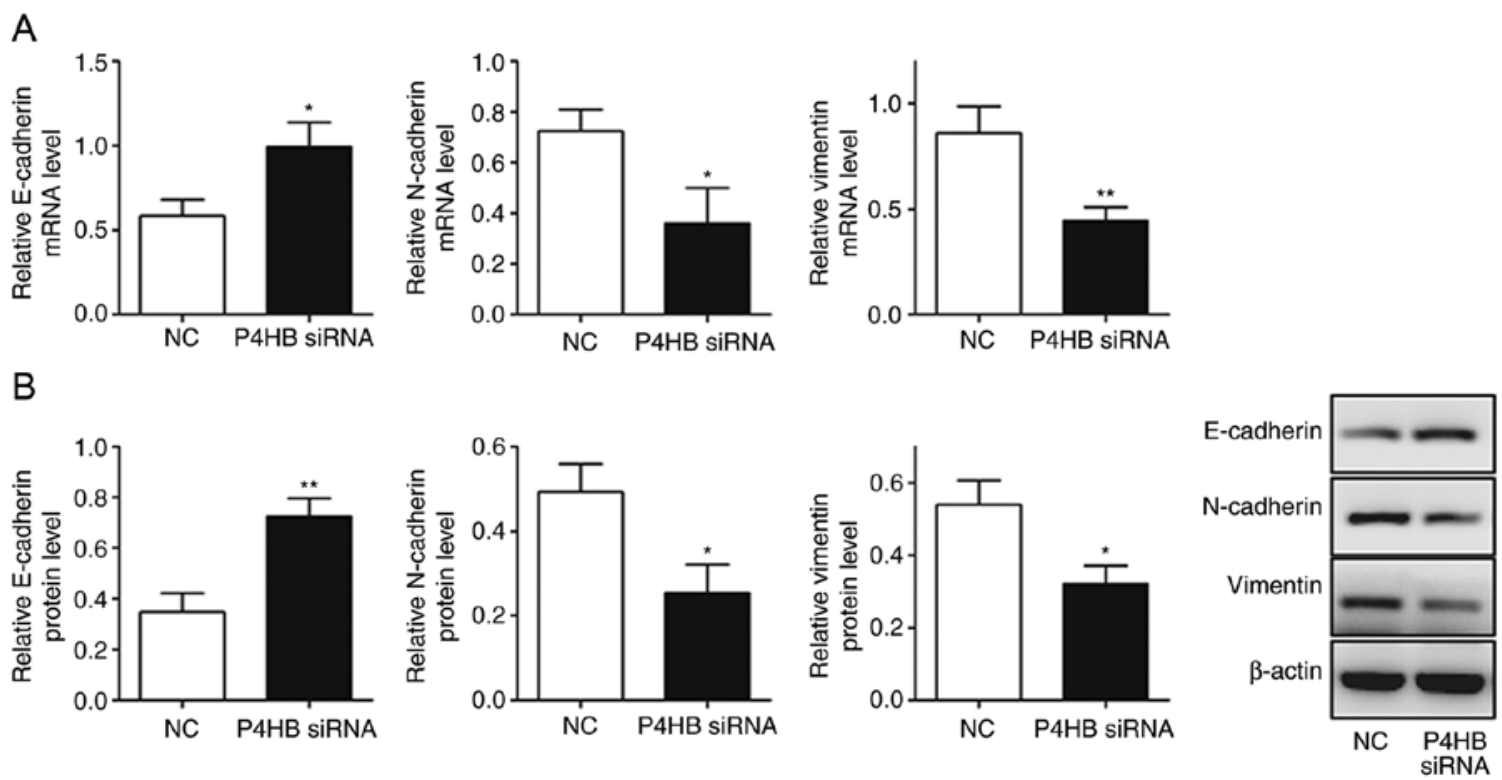

Figure 6. Knockdown of P4HB influences epithelial-mesenchymal transition in HepG2/adriamycin cells. (A) Reverse transcription-quantitative PCR results demonstrated that E-cadherin mRNA expression levels were significantly increased in the P4HB siRNA group, whereas vimentin and N-cadherin levels were significantly reduced. (B) Western blotting results demonstrated that E-cadherin protein expression levels were significantly increased in P4HB siRNA group, whereas vimentin and $\mathrm{N}$-cadherin levels were significantly reduced. Experiments were performed in triplicate. ${ }^{*} \mathrm{P}<0.05$, ${ }^{* *} \mathrm{P}<0.01 \mathrm{vs}$. NC. P4HB, prolyl 4-hydroxylase beta polypeptide; siRNA, small interfering RNA; NC, negative control. 
A

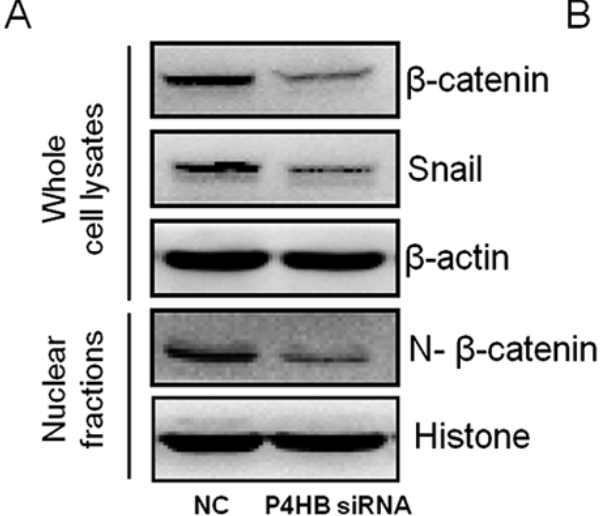

C

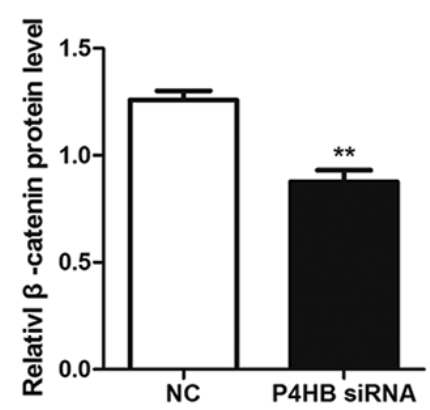

B

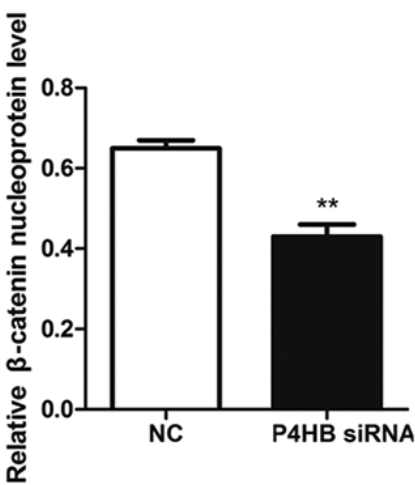

$\mathrm{D}$

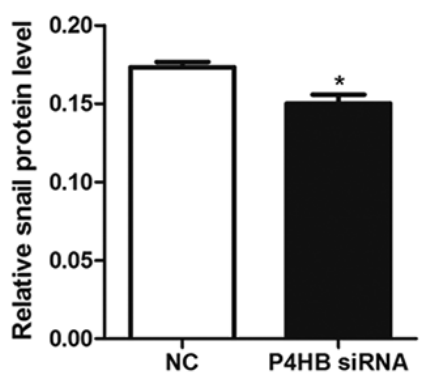

Figure 7. Silencing P4HB suppresses the Snail and $\beta$-catenin pathways in HepG2/adriamycin cells. (A) Expression levels of total $\beta$-catenin, nuclear $\beta$-catenin and Snail were significantly reduced in the P4HB siRNA group. Quantitative results of western blots for (B) nuclear $\beta$-catenin; (C) total $\beta$-catenin; and (D) Snail. Experiments were performed in triplicate. ${ }^{*} \mathrm{P}<0.05,{ }^{* *} \mathrm{P}<0.01$ vs. NC. P4HB, prolyl 4-hydroxylase beta polypeptide; NC, negative control, siRNA, small interfering RNA.

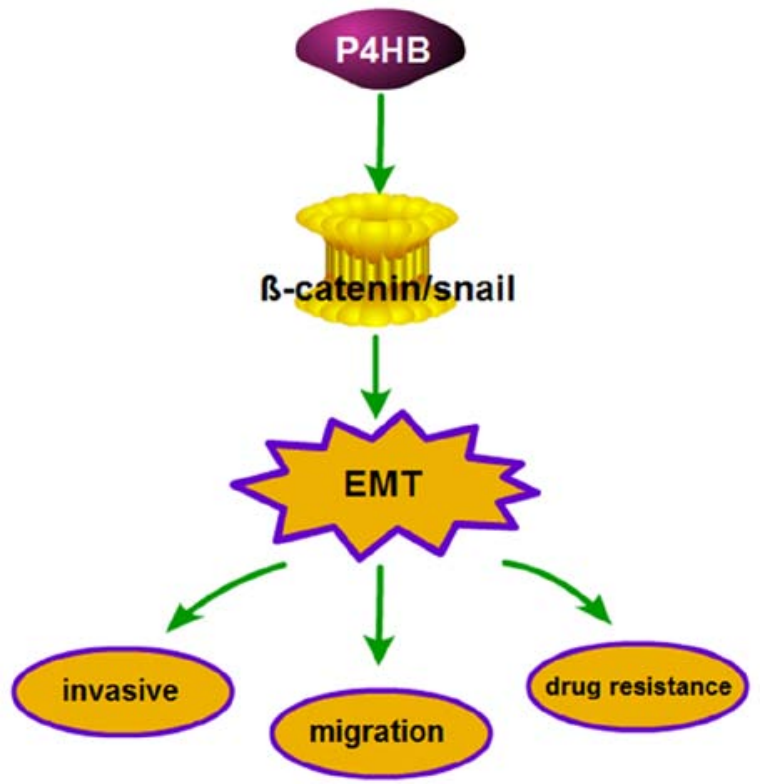

Figure 8. Involvement of P4HB in potential signaling pathways affecting chemosensitivity, invasion and migration in HepG2/ADR cells. P4HB influences chemosensitivity, invasion and migration of HepG2/ADR cells via EMT, which is regulated by the $\beta$-catenin/Snail pathway. P4HB, prolyl 4-hydroxylase beta polypeptide; EMT, epithelial-mesenchymal transition.

revealed that $\mathrm{P} 4 \mathrm{HB}$ expression was significantly upregulated in adriamycin-resistant HepG2/ADR cells, compared with the parental HepG2 cell lines. Silencing P4HB increased the sensitivity of adriamycin-resistant cells to adriamycin. In addition, HepG2/ADR cells exhibited increased invasion and migration abilities, whereas the knockdown of P4HB significantly decreased cell viability and the number of invasive and migratory cells. Notably, the knockdown of P4HB inhibited EMT in HepG2/ADR cells. Overall, the current findings indicate that P4HB knockdown may enhance the sensitivity of HepG2/ADR cells to ADR, and inhibit its invasive and migratory ability.

EMT is a complex molecular program that regulates changes to cell morphology and function during embryogenesis and tissue development (15). During EMT, epithelial cells acquire enhanced motility and invasiveness that are typical of mesenchymal cells. EMT also contributes to tumor progression and metastasis (31). Emerging evidence suggests that cells undergoing EMT have increased chemotherapy resistance, and abnormal activation of genes associated with drug metabolism $(19,32)$. This indicates that EMT is closely associated with chemotherapy resistance in tumor cells. Consistent with these findings, the present study demonstrated the involvement of $P 4 H B$ in chemoresistance in adriamycin-resistant HepG2/ADR cells, whereas P4HB knockdown resulted in reduced EMT and enhanced chemosensitivity.

Snail is a member of the zinc finger transcription factor family and is an important regulatory factor in tumorigenesis which can inhibit gene transcription via competitive binding to promoter sequences (33-35). The phenotypic transformation of epithelial cells to mesenchymal cells results in the occurrence of EMT (36). The data of the present study demonstrated that the knockdown of P4HB significantly decreased the expression of 
Snail in HepG2/ADR cells. $\beta$-catenin is the core component of the Wnt signaling pathway regulates the transcription of several downstream target genes of Wnt, such as cyclin D1, c-myc and vimentin, which mediates metastasis and invasion (37). Snail and $\beta$-catenin have been reported to regulate various cellular processes, such as cancer cell proliferation, apoptosis, invasion, metastases and EMT in colorectal cancer cells (38). The present study demonstrated that the knockdown of P4HB significantly decreased the expression of total and nuclear $\beta$-catenin, and downregulated the expression of Snail. This indicates that $P 4 H B$ may influence the EMT process via the $\beta$-catenin/Snail pathway.

In summary, the present study provides evidence that $P 4 H B$ protects HepG2 cells from ADR. Furthermore, the data demonstrate the role of $\mathrm{P} 4 \mathrm{HB}$ in the chemosensitivity, invasion and migration of HepG2/ADR cells may be mediated via EMT, which is regulated by the $\beta$-catenin/Snail pathway. Thus, $\mathrm{P} 4 \mathrm{HB}$ may represent a novel target to treat liver cancer with acquired ADR resistance. It is well known that $\mathrm{P} 4 \mathrm{HB}$ and its downstream targets may induce EMT; however, the mechanisms by which P4HB regulates EMT remain to be deciphered.

\section{Acknowledgements}

Not applicable.

\section{Funding}

The present study was funded by the National Natural Science Foundation of China (grant nos. 81703791 and 81873178), Shanghai Municipal Commission of Health and Family Planning (grant no. 201740318), Talents Training Program of Seventh People's Hospital of Pudong Health and Family Planning Commission of Shanghai (grant no. PWRq2017-02), Science and Technology Development Fund of Shanghai Pudong New Area (grant no. PKJ2016-Y50) and Talents Training Program of Seventh People's Hospital of Shanghai University of Traditional Chinese Medicine (grant nos. QMX2017-01, XX2017-04 and XX2017-06).

\section{Availability of data and materials}

The datasets used and/or analyzed during the present study are available from the corresponding author on reasonable request.

\section{Authors' contributions}

WX ,YS and JW conceived and designed the study. XM, JW, JZ, XKM and NZ performed the experiments. WX, YS and $\mathrm{XM}$ analyzed the data and wrote the manuscript. WX, JM, JW, XKM and NZ reviewed and edited the manuscript. All authors read and approved the manuscript. All authors read and approved the final manuscript.

\section{Ethics approval and consent to participate}

Not applicable.

\section{Patient consent for publication}

Not applicable.

\section{Competing interests}

The authors declare that they have no competing interests.

\section{References}

1. Bray F, Ferlay J, Soerjomataram I, Siegel RL, Torre LA and Jemal A: Global cancer statistics 2018: GLOBOCAN estimates of incidence and mortality worldwide for 36 cancers in 185 countries. CA Cancer J Clin 68: 394-424, 2018.

2. Torre LA, Bray F, Siegel RL, Ferlay J, Lortet-Tieulent J and Jemal A: Global cancer statistics, 2012. CA Cancer J Clin 65: 87-108, 2015.

3. Raoul JL, Kudo M, Finn RS, Edeline J, Reig M and Galle PR: Systemic therapy for intermediate and advanced hepatocellular carcinoma: Sorafenib and beyond. Cancer Treat Rev 68: 16-24, 2018.

4. El Dika I and Abou-Alfa GK: The role (if any) of chemotherapy in hepatocellular carcinoma. Lancet Gastroenterol Hepatol 2: 387-389, 2017.

5. Zhu Q, Li N, Zeng X, Han Q, Li F, Yang C, Lv Y, Zhou Z and Liu Z: Hepatocellular carcinoma in a large medical center of China over a 10-year period: Evolving therapeutic option and improving survival. Oncotarget 6: 4440-4450, 2015.

6. Pan LH, Zhao C and Ma YL: Is Y90 radioembolization superior or comparable to transarterial chemoembolization for treating hepatocellular carcinoma? Gastroenterology 152: 1627-1628, 2017.

7. Peck-Radosavljevic M: Drug therapy for advanced-stage liver cancer. Liver Cancer 3: 125-131, 2014.

8. Govaere O, Wouters J, Petz M, Vandewynckel YP, Van den Eynde K, Van den Broeck A, Verhulst S, Dollé L, Gremeaux L, Ceulemans A, et al: Laminin-332 sustains chemoresistance and quiescence as part of the human hepatic cancer stem cell niche. J Hepatol 64: 609-617, 2016.

9. Li Y, Ye Y, Feng B and Qi Y: Long noncoding RNA lncARSR promotes doxorubicin resistance in hepatocellular carcinoma via modulating PTEN-PI3K/Akt pathway. J Cell Biochem 118: 4498-4507, 2017.

10. Noiva R: Protein disulfide isomerase: The multifunctional redox chaperone of the endoplasmic reticulum. Semin Cell Dev Biol 10: 481-493, 1999.

11. Xia W, Zhuang J, Wang G, Ni J, Wang J and Ye Y: P4HB promotes HCC tumorigenesis through downregulation of GRP78 and subsequent upregulation of epithelial-to-mesenchymal transition. Oncotarget 8: 8512-8521, 2017.

12. Sun S, Wong TS, Zhang XQ, Pu JK, Lee NP, Day PJ, Ng GK, Lui WM and Leung GK: Protein alterations associated with temozolomide resistance in subclones of human glioblastoma cell lines. J Neurooncol 107: 89-100, 2012.

13. Lee D, Sun S, Ho AS, Kiang KM, Zhang XQ, Xu FF and Leung GK: Hyperoxia resensitizes chemoresistant glioblastoma cells to temozolomide through unfolded protein response. Anticancer Res 34: 2957-2966, 2014.

14. Wang SM, Lin LZ, Zhou DH, Zhou JX and Xiong SQ: Expression of prolyl 4-hydroxylase beta-polypeptide in non-small cell lung cancer treated with Chinese medicines. Chin J Integr Med 21: 689-696, 2015.

15. Thiery JP and Sleeman JP: Complex networks orchestrate epithelial-mesenchymal transitions. Nat Rev Mol Cell Biol 7: 131-142, 2006.

16. Wilson C, Nicholes K, Bustos D, Lin E, Song Q, Stephan JP, Kirkpatrick DS and Settleman J: Overcoming EMT-associated resistance to anti-cancer drugs via Src/FAK pathway inhibition. Oncotarget 5: 7328-7341, 2014.

17. Sánchez-Tilló E, Liu Y, de Barrios O, Siles L, Fanlo L, Cuatrecasas M, Darling DS, Dean DC, Castells A and Postigo A: EMT-activating transcription factors in cancer: Beyond EMT and tumor invasiveness. Cell Mol Life Sci 69: 3429-3456, 2012.

18. Li Y, VandenBoom TG II, Kong D, Wang Z, Ali S, Philip PA and Sarkar FH: Up-regulation of miR-200 and let-7 by natural agents leads to the reversal of epithelial-to-mesenchymal transition in gemcitabine-resistant pancreatic cancer cells. Cancer Res 69: 6704-6712, 2009.

19. Li QQ, Xu JD, Wang WJ, Cao XX, Chen Q, Tang F, Chen ZQ, Liu XP and Xu ZD: Twist1-mediated adriamycin-induced epithelial-mesenchymal transition relates to multidrug resistance and invasive potential in breast cancer cells. Clin Cancer Res 15: 2657-2665, 2009. 
20. Heerboth S, Housman G, Leary M, Longacre M, Byler S, Lapinska K, Willbanks A and Sarkar S: EMT and tumor metastasis. Clin Transl Med 4: 6, 2015.

21. Palma Cde S, Grassi ML, Thomé CH, Ferreira GA, Albuquerque D, Pinto MT, Ferreira Melo FU, Kashima S, Covas DT, Pitteri SJ and Faça VM: Proteomic analysis of epithelial to mesenchymal transition (EMT) reveals cross-talk between SNAIL and HDAC1 proteins in breast cancer cells. Mol Cell Proteomics 15: 906-917, 2016.

22. Wang Y, Shi J, Chai K, Ying X and Zhou BP: The Role of Snail in EMT and tumorigenesis. Curr Cancer Drug Targets 13: 963-972, 2013

23. Angers S and Moon RT: Proximal events in Wnt signal transduction. Nat Rev Mol Cell Biol 10: 468-477, 2009.

24. Nowicki A, Sporny S and Duda-Szymańska J: $\beta$-catenin as a prognostic factor for prostate cancer (PCa). Cent European J Urol 65: 119-123, 2012.

25. Ghahhari NM and Babashah S: Interplay between microRNAs and WNT/ $\beta$-catenin signalling pathway regulates epithelial-mesenchymal transition in cancer. Eur J Cancer 51: 1638-1649, 2015.

26. Chen W, Yang J,Zhang Y, Cai H, Chen X and Sun D: Regorafenib reverses HGF-induced sorafenib resistance by inhibiting epithelial-mesenchymal transition in hepatocellular carcinoma. FEBS Open Bio 9: 335-347, 2019.

27. Roy S, Kar M, Roy S, Saha A, Padhi S and Banerjee B: Role of $\beta$-catenin in cisplatin resistance, relapse and prognosis of head and neck squamous cell carcinoma. Cell Oncol (Dordr) 41: 185-200, 2018

28. Wang D, Qian G, Wang J, Wang T, Zhang L, Yang P and Lin F Visfatin is involved in the cisplatin resistance of osteosarcoma cells via upregulation of Snail and Zeb1. Cancer Biol Ther 20: 999-1006, 2019.

29. Patel N, Garikapati KR, Makani VKK, Nair AD, Vangara N, Bhadra U and Pal Bhadra M: Regulating BMI1 expression via miRNAs promote mesenchymal to epithelial transition (MET) and sensitizes breast cancer cell to chemotherapeutic drug. PLoS One 13: e0190245, 2018.

30. Livak KJ and Schmittgen TD: Analysis of relative gene expression data using real-time quantitative PCR and the 2(-Delta Delta $\mathrm{C}(\mathrm{T}))$ method. Methods 25: 402-408, 2001
31. Nieto MA, Huang RY, Jackson RA and Thiery JP: EMT: 2016. Cell 166: 21-45, 2016.

32. Fischer KR, Durrans A, Lee S, Sheng J, Li F, Wong ST, Choi H, El Rayes T, Ryu S, Troeger J, et al: Epithelial-to-mesenchymal transition is not required for lung metastasis but contributes to chemoresistance. Nature 527: 472-476, 2015.

33. Batlle E, Sancho E, Francí C, Domínguez D, Monfar M, Baulida J and García De Herreros A: The transcription factor snail is a repressor of E-cadherin gene expression in epithelial tumour cells. Nat Cell Biol 2: 84-89, 2000.

34. Cano A, Pérez-Moreno MA, Rodrigo I, Locascio A, Blanco MJ, del Barrio MG, Portillo F and Nieto MA: The transcription factor snail controls epithelial-mesenchymal transitions by repressing E-cadherin expression. Nat Cell Biol 2: 76-83, 2000.

35. Peinado H, Ballestar E, Esteller M and Cano A: Snail mediates E-cadherin repression by the recruitment of the Sin3A/histone deacetylase 1 (HDAC1)/HDAC2 complex. Mol Cell Biol 24: 306-319, 2004

36. Pastushenko I, Brisebarre A, Sifrim A, Fioramonti M, Revenco T, Boumahdi S, Van Keymeulen A, Brown D, Moers V, Lemaire $\mathrm{S}$, et al: Identification of the tumour transition states occurring during EMT. Nature 556: 463-468, 2018.

37. MacDonald BT, Tamai $\mathrm{K}$ and $\mathrm{He} \mathrm{X}$ : Wnt/beta-catenin signaling: Components, mechanisms, and diseases. Dev Cell 17: 9-26, 2009.

38. Liang G, Fang X, Yang Y and Song Y: Silencing of CEMIP suppresses Wnt/ $\beta$-catenin/Snail signaling transduction and inhibits EMT program of colorectal cancer cells. Acta Histochem 120: 56-63, 2018.

This work is licensed under a Creative Commons Attribution-NonCommercial-NoDerivatives 4.0 International (CC BY-NC-ND 4.0) License. 